\title{
Humic acid removal from water using a novel fabricated antifouling carbon nanotube bucky - paper membrane and effect of operating parameters
}

\author{
Jafari A. ${ }^{1}$, Nasseri S. ${ }^{2,3}$, Nabizadeh R. ${ }^{3}$, Mousavi S.A. ${ }^{4}$, Rezaee R. ${ }^{5}$ and Mahvi A.H. ${ }^{2,3,6, *}$ \\ ${ }^{1}$ Department of Environmental Health Engineering, School of Health, Lorestan University of Medical Sciences, Khorramabad, Iran \\ ${ }^{2}$ Center for Water Quality Research (CWQR), Institute for Environmental Research (IER), Tehran University of Medical Sciences, Tehran, \\ Iran \\ ${ }^{3}$ Department of Environmental Health Engineering, School of Public Health, Tehran University of Medical Sciences, Tehran, Iran \\ ${ }^{4}$ Department of Chemical and Petroleum Engineering, Sharif University of Technology, Tehran, Iran \\ ${ }^{5}$ Kurdistan Environmental Health Research Center, Kurdistan University of Medical Sciences, Sanandaj, Iran \\ ${ }^{6}$ Center for Solid Waste Research (CSWR), Institute for Environmental Research (IER), Tehran University of Medical Sciences, Tehran, \\ Iran \\ Received: 30/05/2015, Accepted: 11/04/2017, Available online: 22/09/2017 \\ *to whom all correspondence should be addressed: \\ e-mail: ahmahvi@yahoo.com
}

\section{Abstract}

In present work, a novel supported bucky paper (BP) membrane was fabricated and evaluated for humic acid (HA) removal from water. For better understanding the effect of operating variables, response surface methodology (RSM) was also applied. Three independent parameters namely TOC concentration (5, 10 and 15 $\left.\mathrm{mg} \mathrm{\textrm {I } ^ { - 1 }}\right)$, operating time $(10,20$ and $30 \mathrm{~min})$ and transmembrane pressure (TMP) (1, 2 and 3 bar) were selected for TOC removal (\%) and permeate flux analysis.

The results revealed that the membrane could effectively remove $\mathrm{HA}$ primarily through electrostatic repulsion and then adsorption mechanisms. The study also showed that about $65 \%$ and $35 \%$ of the removed HA were through repulsion and adsorption mechanisms respectively. Based on analysis of variance (ANOVA), it was showed that the effect of TMP was strongly significant on the removal and flux (P-value $<0.05$ ). In addition, statistical test confirmed that RSM based on the Box-Behnken was a suitable method for optimizing the main operating variables for $\mathrm{HA}$ rejection using $B P$ membrane $\left(R^{2}=0.97\right)$. At optimum condition (TMP of 1.5 bar, TOC concentration of 12.7 $\mathrm{mg} \mathrm{l}^{-1}$ ) and operating time of $13.5 \mathrm{~min}$, removal obtained $67.4 \%$ and the flux was $233.4 \mathrm{~lm}^{-2} \mathrm{~h}^{-1}$.

In general, the synthesized BP membrane showed a relatively good rejection of $\mathrm{HA}$ and revealed antifouling properties over the filtration time.

Keywords: Filtration, natural organic matter; carbon nanotubes, response surface methodology, Box- Behnken

1. Introduction
Natural organic matter (NOM) is defined as complex mixture of organic materials entering to natural watercourse from decay products of plants and animals (Crittenden et al., 2012; Sillanpää, 2015). NOM content varies in different waters. It can be in the range of 1 to 20 $\mathrm{mg} / \mathrm{L}$ (as total organic carbon (TOC)) in surface waters (Crittenden et al., 2012).From health significance point, NOM can react with free chlorine and form carcinogenic disinfection by produces (DBPs) in drinking water. Moreover, NOM significantly affect the various water quality parameters and treatment processes. It can complex with metals and some hazard organic chemicals (e.g. pesticides), making the consequent problems. Furthermore, NOM affect the necessity for and application of water treatment chemicals (coagulants and disinfectants) so that increase the required doses to obtain effective performance (Crittenden et al., 2012). Therefore, NOM removal from waters is a challenging topic, and an efficient treatment process is required. Different technologies with varying degrees of success have been proposed for NOM removal include coagulation and flocculation ,electrocoagulation, ion exchange, adsorption, membrane technology, and advanced oxidation processes (Jafari et al., 2015; Mahvi et al., 2009; Mahvi et al., 2011; Moussavi et al., 2014; Rezaee et al., 2014; Sillanpää, 2015).

Membrane technology, as an environmentally friendly and effective option, has increasingly been regarded for different pollutants removal from water. Commonly reverse osmosis (RO) and nanofiltration (NF) membranes are used for water desalination and softening. NOM mixtures can also be efficiently removed via these high pressure membranes (Zazouli et al., 2008). In recent decade low-pressure membranes such as ultrafiltration (UF) has proven to be a reliable and promising method for 
water treatment. However, UF membrane has some drawbacks. The most common drawback with UF membrane for NOM removal is membrane fouling. NOM can adsorb to membranes, obstruct the membrane pores and lead to a rapid decline in water permeability through the membrane (Crittenden et al., 2012; Zazouli et al., 2010). Therefore, NOM removal by UF membrane with less problem and higher efficiency has been considered by many researchers (Jafari et al., 2015; Song et al., 2011).

In recent years various nanomaterials have been widely applied for water and wastewater treatment aspects especially for novel membranes fabrication and modification (Dumée et al., 2011; Jafari et al., 2015; Rezaee et al., 2015). Accordingly Carbon nanotube (CNT) as a dramatic product of nanotechnology has been used for new type of membrane synthesis and application (Dumée et al., 2011; Gilani et al., 2013; Vatanpour et al., 2011).

Bucky paper (BP), a new type of membranes, is a very easy made and flexible thin sheet of functionalized CNTs which stand together after vacuum filtration. BP has been made and applied for different purposes due to its unique characteristics (Cooper et al., 2003; Do et al., 2011; Dumée et al., 2010; Sears et al., 2010; Sweetman et al., 2013). Accordingly, it can effectively be used for water purification because of its flexibility and high pollutants removal. Dumée et al fabricated a BP membrane and successfully investigated for distillation (Dumée et al., 2011). It was also reported that a fabricated $B P$ with pore size of $\sim 41 \mathrm{~nm}$ could remove humic acid (HA) in a dead end operation system (Yang et al., 2013). Furthermore it was very effective in removal of biological agents such as Escherichia coli from water (Sweetman et al., 2013).

The BP characteristics depend on some variables such as CNTs types (single walled or multi walled), synthesis procedure, CNT loading in the dispersion, applied vacuum or pressure and solvent type (Li and Kröger, 2012; Muramatsu et al., 2005; Smajda et al., 2007; Zhang et al., 2014).

Unmodified CNTs do not remain in suspension state in a solvent and settle down after a while. In addition they agglomerate in combination with polymers for matrix membrane synthesis. This problem can be solved through surfactants addition or functionalization. In functionalization of CNTs using mixture of nitric acid and sulfuric acid, carboxyl and hydroxyl groups are induced which improve the dispersion and enhance the tensile strength of the fabricated BP. (Xu et al., 2008; Zhang et al., 2014).

BP fabrication is conducted using vacuum filtration of about 1 bar (Smajda et al., 2007) or pressurized method of 1 to 12 bar (Zhang et al., 2014). High pressures decrease the porosity of the BP due to the flexibility of the spongy CNT network structure (Zhang et al., 2014).

BP has generally been fabricated as free standing membranes in which the fabricated membrane peeled off and use after filtering the CNT suspension through a filter. However in this work, a novel supported bucky-paper was fabricated and used for humic acid (HA) rejection. Design of experiments (DOE) method was also applied for this study as a known method in response surface methodology (RSM) (Çoruh and Elevli, 2015; Jafari et al., 2014; Rezaee et al., 2014). For this purpose, three main variables in terms of transmembrane pressure (TMP), humic acid concentration and filtration time with three levels were employed.

The aim of this work is to evaluate a fabricated BP membrane for NOM rejection and analysis the role of operating parameters on the performance of the membrane.

\section{Materials and methods}

\subsection{Membrane synthesis and characterization}

In this study multi-walled carbon nanotube (MWCNTs) (purity of 95\% and outer diameter of $10-50 \mathrm{~nm}$ and length of $10 \mu \mathrm{m}$ ) was purchased from Petroleum Research Centre (Iran). Functionalization process was performed according to the method described by Naghizadeh et al., using a mixture of sulfuric and nitric acids $(3: 1 \mathrm{~V} / \mathrm{V})$ to obtain functionalized CNT (Naghizadeh et al., 2013) . Certain amount of functionalized CNTs $(0.2 \mathrm{~g})$ was placed in $100 \mathrm{ml}$ of ethanol with certain amount of ethyl acetate $(0.02 \mathrm{~g})$ as polymeric binder under sonicating ( $30 \mathrm{kHz}$ for $1 \mathrm{~h})$ at room temperature $\left(\sim 25{ }^{\circ} \mathrm{C}\right)$ to gain a uniform dispersion. The certain volume of this suspension was then taken and vacuumed using a vacuum pump (-0.6 bar) through a nonwoven polyester substrate filter $(150 \mu \mathrm{m}$ thickness and mean pore diameter of $10 \mu \mathrm{m})$. Then it was allowed to dry in an oven at $40{ }^{\circ} \mathrm{C}$ for $24 \mathrm{~h}$. Synthesized BP was then characterized and employed for HA removal.

\subsection{Membrane characterization}

Membrane surface and cross section morphology were analyzed via field emission scanning electron microscopy (FESEM) (Hitachi-S4160). Further analysis of membrane pores and structure was conducted using an image analyzer software (Abràmoff et al., 2004).

Water contact angle (CA) as an important factor for membrane hydrophilicity was determined using the conventional sessile drop method (Data physics, OCA 15 plus). Contact angles small amount of deionized water $(4 \mu \mathrm{L})$ on the surface of BP membrane were determined at room temperature. The mean value of at least five water droplets was presented as the result of this measurement.

The porosity of the BP was analyzed using $\mathrm{N}_{2}$ adsorption/desorption using an ASAP-2010 porosimeter (Micromeritics Corporation GA) and the specific surface area of the BP was calculated using the Brunauer-EmmettTeller (BET) method.

\subsection{Membrane flux}

Membrane flux (J) $\left(1 \mathrm{~m}^{-2} \mathrm{~h}^{-1}\right)$ was measured using the following equation

$$
J=\left(\frac{V}{A m \cdot t}\right)
$$


Where $\mathrm{V}(\mathrm{L})$ is the volume of permeate water, $t$ denotes for operating time $(h)$ and $A_{m}\left(m^{2}\right)$ stands for effective surface area of membrane.

\subsection{Experimental set up}

The digital photograph of applied set up for this study is shown in Fig. 1. The main parts of the set up were: a $2-\mathrm{L}$ feed (storage) tank, a low-pressure pump, membrane cell ( $9.6 \mathrm{~cm}^{2}$ of effective surface area), flow meters, gauges and valves. Temperature control system was also applied to maintain the temperature of feed solution at $24 \pm 1^{\circ} \mathrm{C}$. For process analysis the synthetic the pump was turned on to flow the solution the to the membrane cell. At different interval times filtered water was collected for analysis and the concentrate was continuously returned to the storage (feed) tank.

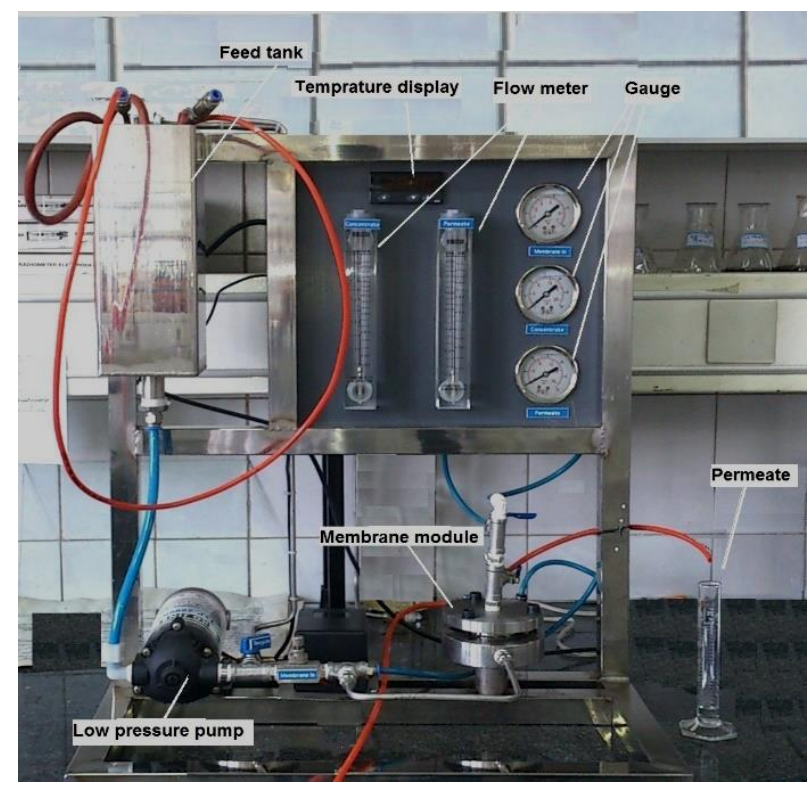

Figure 1. Set up experiment

\subsection{NOM model solution and analysis}

In this study, NOM model solution was synthetically prepared by dissolved humic acid (HA) (Acros organics company, NJ USA) in distilled water. In this study NOM concentration was analyzed using a TOC analyzer (TOCVCPH, Shimadzu Japan).

The removal percentage was calculated from the following equation:

$$
R(\%)=\left(1-\frac{C p}{C f}\right) \times 100
$$

Where $\mathrm{R}$ refers to rejection, $\mathrm{Cp}$ is the TOC concentration of permeate and $\mathrm{Cf}$ is the TOC concentration of feed. The adsorbed fraction was calculated using the following mass balance equation in a condition that the concentrate was recycled to feed tank for $60 \mathrm{~min}$.

$$
\operatorname{Mads}(\%)=\frac{\mathrm{CfVf}-\left[\mathrm{CtVt}+\sum \mathrm{CpVp}\right] \times 100}{\mathrm{CfVf}}
$$

Where, Mads is the portion of adsorbed TOC per effective membrane area, $C_{f}, C_{t}$ and $C_{p}$ are the concentrations of TOC in feed tank at the beginning, the concentrations of TOC in feed tank at the end of filtration and concentration of TOC in permeate, respectively. Differences between Eq. (21) and Eq. (3) reveal the repulsed TOC fraction.

\subsection{Experiments design}

In order to obtain the effect of different operating parameters on performance of the membrane, response surface methodology (RSM) was employed. For this aim, Box- Behnken method with three main variables and three levels was used for filtration modelling and optimization. Main variables (and the related levels) include applied pressure (1, 2 and 3 bar), initial TOC concentration (5, 10 and $15 \mathrm{mg} \mathrm{l}^{-1}$ ) and operating time (10, 20 and $30 \mathrm{~min}$ ). Table 1 presents the experimental design and related results of the experiment runs for the responses (flux and HA rejection).

In this study, other conditions such as $\mathrm{pH}$ and temperature kept constant and a new membrane was used for each run of experiments and the runs were carried out based on randomized order by Design Expert software (trial version 7.0).

\section{Results and discussion}

\subsection{Membrane characteristics}

Digital photograph of the fabricated BP is shown in Fig. 2. The fabricated supported membrane was enough flexible and can be folded and cut with scissors. As displayed in the image, the white margin reveals the supported nonwoven fabric and the place of sealing O-ring of vacuum system.

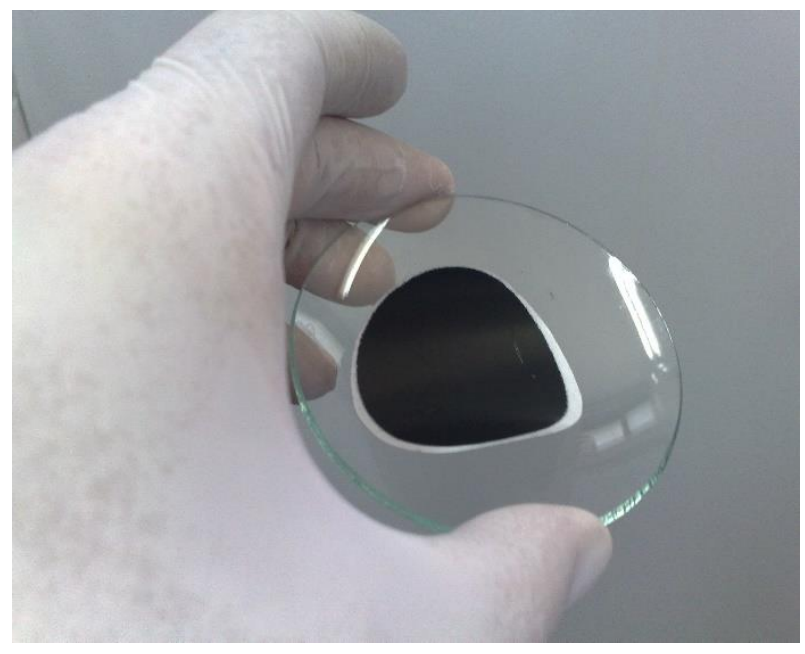

Figure 2. Digital photograph of the BP membrane

Figs. 3 and 4 depict the surface and cross section microphotograph of BP respectively. As shown, CNTs have formed a network like structure on the surface and in nonwoven substrate. Since the CNTs penetrated in porous structure of non-woven substrate, created a porous network and enhanced the mechanical strength of the membrane. 
The mean of surface pore diameter of the membrane from FESM image was $30 \pm 13 \mathrm{~nm}$. This value of diameters is in the range of a typical UF membrane. In spite of common polymeric membranes, the size and morphology of BPs vary considerably depend on the fabrication process. From our analysis, the shape of the pores is not typical and a wide range of size distribution exists. As previously noted, some parameters such as dispersion quality and specially CNTs properties including length, diameter, functionalization method and pressure condition can affect BP pores characteristics (Li and Kröger, 2012; Muramatsu et al., 2005; Smajda et al., 2007; Zhang et al., 2014). Normally, CNTs with smaller length and lower content develop small pore sizes (Li and Kröger, 2012) which is an important variable for pollutants rejection via membrane size exclusion.

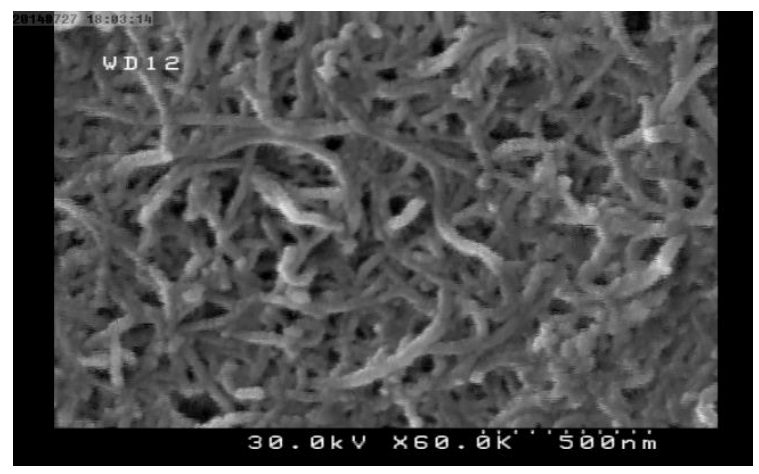

Figure 3. FESEM image of top surface BP

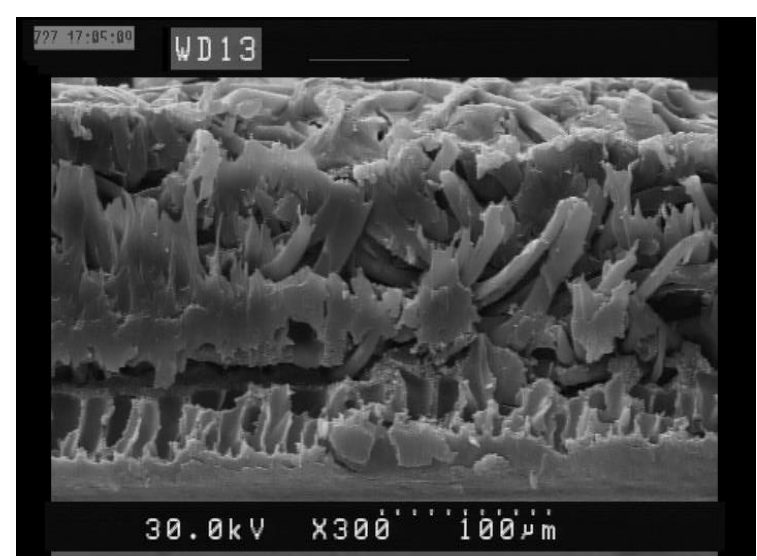

Figure 4. Cross sectional FESEM image of BP on non woven substrate

Fig. 5 depicts the CA of the prepared membrane. CA for synthesized membrane was $45 \pm 3^{\circ}$. Generally, the smaller CA represents higher hydrophilicity. From Fig. 5, static attachment of water droplet on the top surface of the membrane indicates the great hydrophilic property of the membrane. Although, pristine (non-functionalized) CNTs are hydrophobic in nature, it is well known that introducing hydroxyl (-OH) and carboxylic $(-\mathrm{OOH})$ functional groups can change the tendency of the membrane to be wet, improve the hydrophilicity and enhance the membrane flux (Yin et al., 2013).
The overall porosity of the BP membrane was calculated about $70 \%$. The porosity of BP membrane is primarily affected by CNTs type, length, CNT loading, preparation condition and sonication time (Li and Kröger, 2012; Yang et al., 2013). Different range of porosity from $30 \%$ to $90 \%$ have been reported based on different experiments (Cranford and Buehler, 2010). For example, it was reported that CNTs with higher length built higher porosity (Li and Kröger, 2012) and lower loaded CNTs developed lower porosity (Li and Kröger, 2012). Generally porosity incorporated with other properties of the membrane such as hydrophilicity is a key factor for membrane performance in terms of flux and antifouling properties (Zhao et al., 2013).

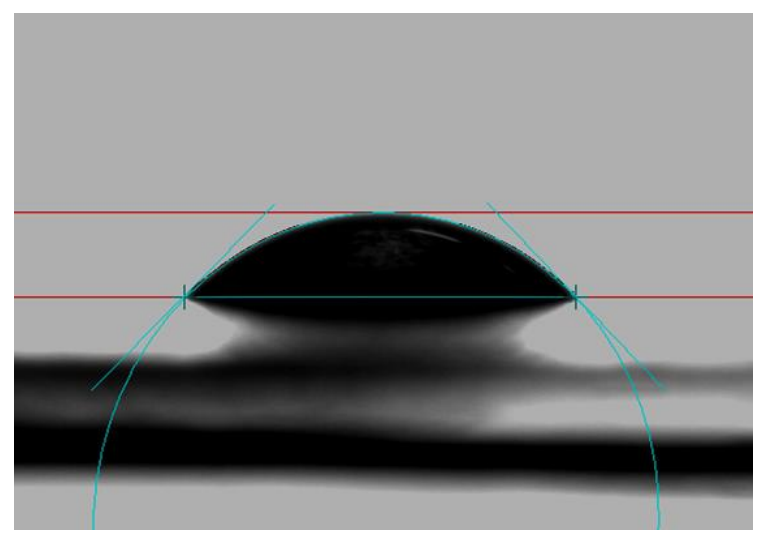

Figure 5. Water contact angle image of the BP

BET surface area of the membrane was calculated about $231 \mathrm{~m}^{2} / \mathrm{g}$. In general, different surface areas related to CNTs could be obtained under different experimental conditions. CNTs surface area can change through modification and blending with other chemicals. After a functionalization process the surface area of pristine CNT can increase from $130 \mathrm{~m}^{2} / \mathrm{g}$ to $171 \mathrm{~m}^{2} / \mathrm{g}$ (Naghizadeh et al., 2013). However, in membrane process surface area is crucial parameter. Higher surface areas of the membrane can provide higher adsorptive or repulsive sites on the membrane that could improve the membrane performance. Hence, higher surface area with negatively charge could be of interest for rejection of substances with the same charge.

\subsection{Membrane pure water flux}

The measured pure water flux $\left(\mathrm{J}_{0}\right)$ for synthesized membrane was $300 \pm 15 \mathrm{Im}^{-2} \mathrm{~h}^{-1}$. The pure water flux of a membrane is mainly a function of pore size. However, other factors affect the flux. In this regard, membrane hydrophilicity is an important factor as previously noted. Furthermore, membrane thickness, compaction and inner properties are important too. The overall thickness of the membrane was measured about $250 \pm 30 \mu \mathrm{m}$ for the synthesized membrane. Amount of CNTs applied for bucky paper preparation and vacuum pressure could affect the membrane thickness, pores and porosity. Generally higher thickness resulted from higher loaded CNTs, prevents water transport across the membrane due to reduction in porosity and blocking the substrate pores. 


\subsection{Effect of main parameters on the rejection and flux}

As shown in Fig. 6 at the beginning of filtration, the rejection occurred primarily by a combination of both adsorption and repulsion. At the starting of filtration, feed TOC of $4.6 \mathrm{mg} \mathrm{l}^{-1}$ reduced to $1.32 \mathrm{mg} \mathrm{l}^{-1}$ in permeate. Meanwhile TOC slightly increased in concentrate and feed. Although this change is not significant, it shows that at up to $30 \mathrm{~min}$ of filtration, the rejection is occurred by both adsorption and repulsion. After exhausting the adsorption capacity, the rejection proceeds by charge repulsion and the permeate curve stands nearly constant. In other word, increase in the feed solution, due to recycling of concentrate, do not affect the membrane rejection performance.

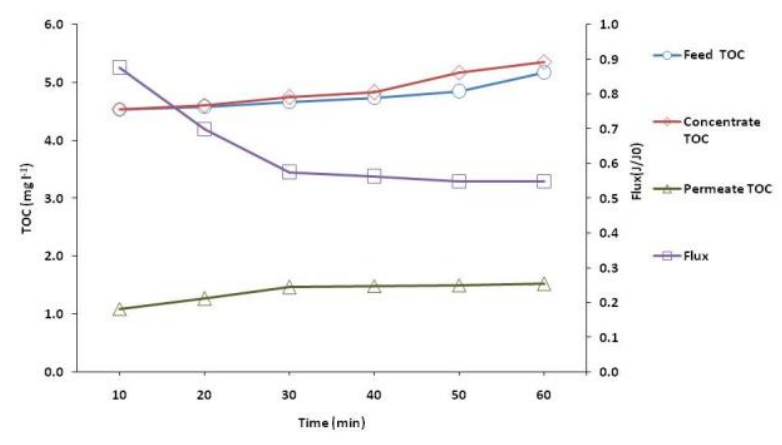

Figure 6. Trend of different elements at filtration of $\mathrm{HA}$ in a loop experiment. (Initial TOC $=4.6 \mathrm{mg} \mathrm{l}^{-1}, \mathrm{pH} \approx 7.5, \mathrm{TMP}=2$ bar)

Fig. 7 shows the different portions of TOC mass calculated by Eq. (2). With regard to Fig.7, about $56.6 \%$ of HA is rejected by charge repulsion and about $30 \%$ is adsorbed by the membrane. These results showed that functionalized CNTs could change the removal mechanism from adsorption to repulsion. From the figure as there are several adsorbing sites on the CNTs, HA is rapidly adsorbed on the sites and after a while, removal is mainly happened through electrostatic repulsion (Fig. 6). In other hand, the

Table 1. The results experimental randomized runs for $\mathrm{HA}$ rejection and the related flux

\begin{tabular}{|c|c|c|c|c|c|}
\hline Run No & A:TMP (Bar) & B:TOC (mg l-1) & C:Time (min) & Flux $\left(\operatorname{Im}^{-2} h^{-1}\right)$ & Rejection (\%) \\
\hline 1 & 3 & 15 & 20 & 228.1 & 45.0 \\
\hline 2 & 1 & 5 & 20 & 165.6 & 84.7 \\
\hline 3 & 2 & 10 & 20 & 296.9 & 63.3 \\
\hline 4 & 2 & 5 & 30 & 202.1 & 65.0 \\
\hline 5 & 3 & 10 & 10 & 375.0 & 29.5 \\
\hline 6 & 2 & 10 & 20 & 275.0 & 61.0 \\
\hline 7 & 1 & 15 & 20 & 109.4 & 69.4 \\
\hline 8 & 2 & 5 & 10 & 312.5 & 64.9 \\
\hline 9 & 1 & 10 & 10 & 187.5 & 75.0 \\
\hline 10 & 2 & 15 & 30 & 163.5 & 57.0 \\
\hline 11 & 1 & 10 & 30 & 164.6 & 74.0 \\
\hline 12 & 2 & 15 & 10 & 250.0 & 61.2 \\
\hline 13 & 3 & 5 & 20 & 281.3 & 50.0 \\
\hline 14 & 2 & 10 & 20 & 285.9 & 63.5 \\
\hline 15 & 3 & 10 & 30 & 166.7 & 47.0 \\
\hline
\end{tabular}

flux declined rapidly at first 30 min of operation (Fig. 6) due to adsorption of HA on the surface and into the pores of BP. However, based on normalized permeate flux ratio $\left(\mathrm{J} / \mathrm{J}_{0}\right)$ during the filtration time (Fig. 6, right vertical axis), about $40 \%$ of flux decline happened in first $30 \mathrm{~min}$, after that a slow slope is seen. Nevertheless, the flux does not decrease more that $45 \%$ after 60 min of operation. Such behaviour pores and increasing of feed TOC due to retentate recirculating to the feed flow. Although UF modification, process alteration and integrated processes have been reported to enhance the UF membrane performance in term of flux decline (Liu et al., 2011; Song et al., 2011), in $\mathrm{BP}$ the decline rate is not as rapid as commercial UF membranes (Song et al., 2011). Functionalized (carboxylated) CNTs effectively reject HA substances and hinder the fouling due to induce negatively charges on membrane surface which effectively improve both the rejection and antifouling property. This is mainly happened through increasing the electrostatic interaction between membrane charge and HA (Song et al., 2011).

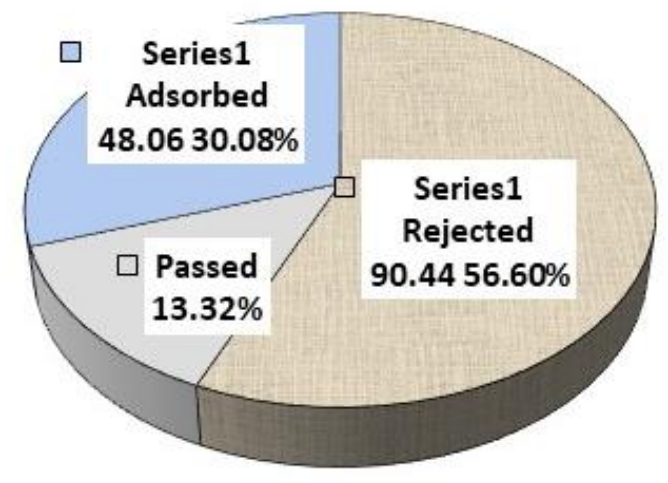

Figure 7. Different portions (repulsed, passed and adsorbed) of HA through filtration by synthesized BP membrane. can be due to gradually adsorption of HA in membrane 
Driving force can also affect the membrane performance in terms of rejection and flux decline in different conditions. The effect of TMP versus time and TOC concentration on $\mathrm{HA}$ rejection have been illustrated by 3D surface plots (Figs. 8-A and 8-C). As shown, with increase of TMP, the rejection decreased. Statistically, according to ANOVA results (Table 2), TMP is the most important parameter on the rejection ( $p$ value $<0.05$ ). Although in some cases it is expected that increase of TMP could form a sieving network by a layer of particles that retain the smaller particles (Crittenden et al., 2012), but this figure shows that higher TMP may create a path for penetrating small molecules or particles. Moreover, flexible structure of BP may be affected by high driving force. From Fig. 8-D and 8-E, increase of flux as a function of TMP increment can be seen, but the increase is not linear. Based on ANOVA results (Table 2) the effect of TMP on the flux is strongly significant ( $p$ value $<0.05$ ).
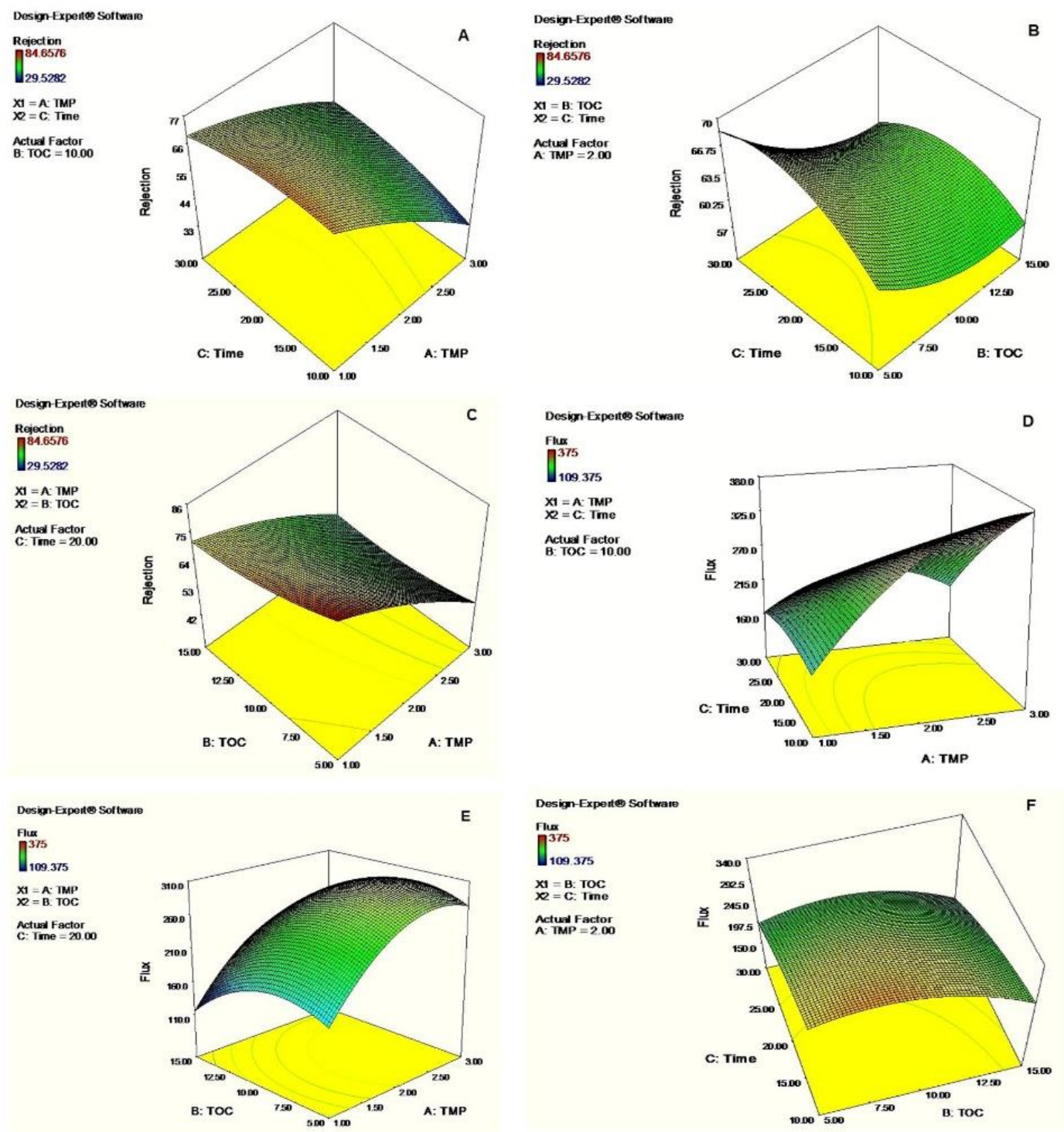

Figure 8. 3D surface plots of variables: $(A)$ rejection as a response of TMP and Time (B) rejection as a response of TOC and Time (C) rejection as a response of TMP and TOC (D) flux as a response of TMP and Time (E) flux as a response of TMP and TOC (F) flux as a response of TOC and Time

Operating time significantly affects the rejection performance ( $p$-value < 0.05), (Table 2). Generally, operating time has a high effect on membrane fouling in case of adsorption of the pollutants by membrane. On the other hand, repulsive mechanism in membrane can increase the membrane lifetime. From Fig. 6 the rate of flux decline is nearly rapid at the beginning of the filtration. As previously noted, negative charges of hydroxylated groups on the membrane can prevent the fouling and flux decline. Since HA has high affinity to pristine CNTs (Naghizadeh et al., 2013), introducing functional groups on the CNTs could significantly increase the rejection properties. 
Accordingly, reduction of adsorption capacity results in reduction of fouling phenomenon.

Furthermore, TOC concentration in the solution affected both the rejection and flux (Fig. 8-B, 8-E and 8-F). Commonly, increase of TOC in the case of TMP increase resulted in accumulation of TOC near the surface of the membrane and consequent concentration polarization phenomenon. From ANOVA results, (Table 2), TOC is significant for rejection and flux ( $p$-value $<0.05$ ). However, increase of TOC may result in reduction of electrostatic charges on the membrane surface and decrease of the charge potential.

Table 2. Analysis of variance (ANOVA) results for flux and rejection of HA

\begin{tabular}{|c|c|c|c|c|c|c|c|c|c|c|}
\hline & \multicolumn{5}{|c|}{ Flux } & \multicolumn{5}{|c|}{ Rejection } \\
\hline & $\begin{array}{l}\text { Sum of } \\
\text { Squares }\end{array}$ & df & $\begin{array}{c}\text { Mean of } \\
\text { Square }\end{array}$ & F Value & $\begin{array}{l}\text { p-value } \\
\text { Prob }>\mathrm{F}\end{array}$ & $\begin{array}{l}\text { Sum of } \\
\text { Squares }\end{array}$ & df & $\begin{array}{c}\text { Mean of } \\
\text { Square }\end{array}$ & $\begin{array}{c}\mathbf{F} \\
\text { Value }\end{array}$ & $\begin{array}{l}\text { p-value } \\
\text { Prob }>F\end{array}$ \\
\hline Model & 73815.27 & 9 & 8201.70 & 63.44 & 0.0001 & 2527.03 & 9 & 280.78 & 15.89 & 0.0036 \\
\hline A-TMP & 22467.58 & 1 & 22467.58 & 173.78 & $<0.0001$ & 2161.58 & 1 & 2161.58 & 122.31 & 0.0001 \\
\hline B-TOC & 5534.40 & 1 & 5534.40 & 42.81 & 0.0012 & 127.75 & 1 & 127.75 & 7.23 & 0.0434 \\
\hline C-Time & 22911.38 & 1 & 22911.38 & 177.21 & $<0.0001$ & 19.27 & 1 & 19.27 & 1.09 & 0.3442 \\
\hline$A B$ & 2.44 & 1 & 2.44 & 0.019 & 0.8961 & 26.45 & 1 & 26.45 & 1.50 & 0.2757 \\
\hline$A C$ & 8594.84 & 1 & 8594.84 & 66.48 & 0.0005 & 85.30 & 1 & 85.30 & 4.83 & 0.0794 \\
\hline$B C$ & 143.50 & 1 & 143.50 & 1.11 & 0.3403 & 4.66 & 1 & 4.66 & 0.26 & 0.6296 \\
\hline$A^{\wedge} 2$ & 8944.56 & 1 & 8944.56 & 69.18 & 0.0004 & 32.95 & 1 & 32.95 & 1.86 & 0.2304 \\
\hline $\mathrm{B}^{\wedge} 2$ & 6093.75 & 1 & 6093.75 & 47.13 & 0.0010 & 25.82 & 1 & 25.82 & 1.46 & 0.2808 \\
\hline$C^{\wedge} 2$ & 651.29 & 1 & 651.29 & 5.04 & 0.0748 & 38.54 & 1 & 38.54 & 2.18 & 0.1998 \\
\hline Residual & 646.43 & 5 & 129.29 & & & 88.36 & 5 & 17.67 & & \\
\hline Lack of Fit & 407.17 & 3 & 135.72 & 1.13 & 0.5001 & 84.50 & 3 & 28.17 & 14.59 & 0.0648 \\
\hline Pure Error & 239.26 & 2 & 119.63 & & & 3.86 & 2 & 1.93 & & \\
\hline
\end{tabular}

\subsection{Model evaluation}

Developed models as the coded values for rejection and flux are as follows.

Flux $\left(\operatorname{Im}^{-2} h^{-1}\right)=285.94+52.99 \times A-26.30 \times B-53.52 C+0.78 \times A \times B-46.35 \times A \times C+5.99 \times B \times C-49.22 \times A 2-40.63 \times B^{2}-13.28 \times C^{2}$

The built modes were evaluated based on the statistical tools. According to $p$-values, both the produced models are significant (Table 2). For the models, determination coefficient $\left(R^{2}\right)$ were 0.99 and 0.97 for flux and rejection, respectively and the adjusted $R^{2}$ and predicted $R^{2}$ are high enough ( $>0.9$ ) that confirm the validity of produced models for flux and rejection.

Furthermore, $p$-values of lack of fit (LOF) were 0.5 and 0.064 for flux and rejection respectively. Insignificancy of LOF values confirms the validity of the developed model for prediction of a process.

\subsection{Optimal condition}

Optimum condition for $\mathrm{HA}$ rejection and flux was obtained. Based on these conditions at TMP of 1.5 bar, TOC concentration of $12.7 \mathrm{mg} \mathrm{l}^{-1}$ and time of $13.5 \mathrm{~min}$, rejection was $67.4 \%$ and the flux was $233.4 \mathrm{~m}^{-2} \mathrm{~h}^{-1}$. This forecast was evaluated by an extra test at the optimal condition. The rejection was obtained $70 \%$ that was near to that was predicted by the model.

\section{Conclusion}

The results of this study revealed that functionalized CNT application as BP membrane can effectively reject $\mathrm{HA}$. The antifouling property of the membrane is promising for future application for NOM rejection. This study also revealed a long life operating of the system with less fouling phenomenon due to inducing of hydrophilic functional groups to BP membrane. It was revealed that the built quadric model can predict the process suitably. Although the membrane has many benefits based on the results of this study, but some challenges still remain including the possible release of nano materials to the finished water. Future studies can focus on the monitoring and possible release of CNT through BP membrane.

\section{Acknowledgment}

The authors greatly acknowledge the CWQR for the support of this research (grant No 22715-46-02-92). The authors also thank the Laboratory staff of Department of Environmental Health Engineering.

\section{References}

Abràmoff M.D., Magalhães P.J. and Ram S.J. (2004), Image processing with ImageJ, Biophotonics international, 11(7), 36-43.

Cooper S.M., Chuang H.F., Cinke M., Cruden B.A. and Meyyappan M. (2003), Gas permeability of a buckypaper membrane, Nano Lett., 3(2), 189-192.

Çoruh S. and Elevli S. (2015), Optimization study of dye removal by cement kiln dust using the central composite design of experiments, Global NEST Journal, 17(1), 93-102.

Cranford S.W. and Buehler M.J. (2010), In silico assembly and nanomechanical characterization of carbon nanotube buckypaper, Nanotechnology, 21(26), 265706.

Crittenden J.C., Trussell R.R., Hand D.W., Howe K.J. and Tchobanoglous G. (2012), MWH's Water Treatment: Principles and Design Wiley.

Do Q.H., Zeng C., Zhang C., Wang B. and Zheng J. (2011), Supercritical fluid deposition of vanadium oxide on multi- 
walled carbon nanotube buckypaper for supercapacitor electrode application, Nanotechnology, 22(36), 365402.

Dumée L., Campbell J.L., Sears K., Schütz J., Finn N., Duke M. and Gray S. (2011), The impact of hydrophobic coating on the performance of carbon nanotube bucky-paper membranes in membrane distillation, Desalination, 283(0), 64-67.

Dumée L.F., Sears K., Schütz J., Finn N., Huynh C., Hawkins S., Duke M. and Gray S. (2010), Characterization and evaluation of carbon nanotube Bucky-Paper membranes for direct contact membrane distillation, J membra Sci, 351(1-2), 36-43.

Gilani N., Towfighi J., Rashidi A., Mohammadi T., Omidkhah M.R. and Sadeghian A. (2013), Investigation of $\mathrm{H}_{2} \mathrm{~S}$ separation from $\mathrm{H}_{2} \mathrm{~S} / \mathrm{CH}_{4}$ mixtures using functionalized and non-functionalized vertically aligned carbon nanotube membranes, Appl. Surf. Sci., 270(0), 115-123.

Jafari A., Mahvi A.H., Godini H., Rezaee R. and Hosseini S.S. (2014), Process optimization for fluoride removal from water by moringa oleifera seed extract, Fluoride, 47(2), 152-160.

Jafari A., Mahvi A.H., Nasseri S., Rashidi A., Nabizadeh R., Rezaee R. and Complex A.S. (2015), Ultrafiltration of natural organic matter from water by vertically aligned carbon nanotube membrane, J Environ Health Sci Eng, 13(1), 51.

Li Y. and Kröger M. (2012), A theoretical evaluation of the effects of carbon nanotube entanglement and bundling on the structural and mechanical properties of buckypaper, Carbon, 50(5), 1793-1806.

Liu T., Chen Z.-I., Yu W.-Z., Shen J.-M. and Gregory J. (2011), Effect of two-stage coagulant addition on coagulation-ultrafiltration process for treatment of humic-rich water, Water Research, 45(14), 4260-4268.

Mahvi A., Maleki A., Rezaee R. and Safari M. (2009), Reduction of humic substances in water by application of ultrasound waves and ultraviolet irradiation, Iranian J Environ Health Sci Eng, 6(4), 233-240.

Mahvi A.H., Malakootian M. and Heidari M.R. (2011), Comparison of polyaluminum silicate chloride and electrocoagulation process, in natural organic matter removal from surface water in Ghochan, Iran, Journal of Water Chemistry and Technology, 33(6), 377-385.

Moussavi S., Ehrampoush M., Mahvi A., Rahimi S. and Ahmadian M. (2014), Efficiency of Multi-Walled Carbon Nanotubes in Adsorbing Humic Acid from Aqueous Solutions, Asian J. Chem., 26(3), 821-826.

Muramatsu H., Hayashi T., Kim Y., Shimamoto D., Kim Y., Tantrakarn K., Endo M., Terrones M. and Dresselhaus M. (2005), Pore structure and oxidation stability of double-walled carbon nanotube-derived bucky paper, Chem. Phys. Lett., 414(4), 444-448.

Naghizadeh A., Nasseri S., Rashidi A., Kalantary R.R., Nabizadeh R. and Mahvi A. (2013), Adsorption kinetics and thermodynamics of hydrophobic natural organic matter (NOM) removal from aqueous solution by multi-wall carbon nanotubes, Water Science \& Technology: Water Supply, 13(2), 273-285.

Rezaee R., Maleki A., Jafari A., Mazloomi S., Zandsalimi Y. and Mahvi A.H. (2014), Application of response surface methodology for optimization of natural organic matter degradation by $\mathrm{UV} / \mathrm{H}_{2} \mathrm{O}_{2}$ advanced oxidation process, J Environ Health Sci Eng, 12(1), 67.

Rezaee R., Nasseri S., Mahvi A.H., Nabizadeh R., Mousavi S.A., Rashidi A., Jafari A. and Nazmara S. (2015), Fabrication and characterization of a polysulfone-graphene oxide nanocomposite membrane for arsenate rejection from water, J Environ Health Sci Eng, 13(1), 1-11.

Sears K., Dumée L., Schütz J., She M., Huynh C., Hawkins S., Duke M. and Gray S. (2010), Recent developments in carbon nanotube membranes for water purification and gas separation, Materials, 3(1), 127-149.

Sillanpää M. (2015), Chapter 1 - General Introduction, in: M. Sillanpää (Ed.), Natural Organic Matter in Water, ButterworthHeinemann. pp. 1-15.

Smajda R., Kukovecz Á., Kónya Z. and Kiricsi I. (2007), Structure and gas permeability of multi-wall carbon nanotube buckypapers, Carbon, 45(6), 1176-1184.

Song H., Shao J., He Y., Hou J. and Chao W. (2011), Natural organic matter removal and flux decline with charged ultrafiltration and nanofiltration membranes, J membra Sci, 376(1-2), 179-187.

Sweetman L.J., Alcock L.J., McArthur J.D., Stewart E.M., Triani G. and Ralph S.F. (2013), Bacterial filtration using carbon nanotube/antibiotic buckypaper membranes, Journal of Nanomaterials, 2013, 23.

Vatanpour V., Madaeni S.S., Moradian R., Zinadini S. and Astinchap B. (2011), Fabrication and characterization of novel antifouling nanofiltration membrane prepared from oxidized multiwalled carbon nanotube / polyethersulfone nanocomposite, J membra Sci, 375(1-2), 284-294.

Xu G., Zhang Q., Zhou W., Huang J. and Wei F. (2008), The feasibility of producing MWCNT paper and strong MWCNT film from VACNT array, Appl. Phys. A, 92(3), 531-539.

Yang X., Lee J., Yuan L., Chae S.-R., Peterson V.K., Minett A.I., Yin Y. and Harris A.T. (2013), Removal of natural organic matter in water using functionalised carbon nanotube buckypaper, Carbon, 59(0), 160-166.

Yin J., Zhu G. and Deng B. (2013), Multi-walled carbon nanotubes (MWNTs)/polysulfone (PSU) mixed matrix hollow fiber membranes for enhanced water treatment, Journal of Membrane Science, 437(0), 237-248.

Zazouli M., Ulbricht M., Nasseri S. and Susanto H. (2010), Effect of hydrophilic and hydrophobic organic matter on amoxicillin and cephalexin residuals rejection from water by nanofiltration, Iranian J Environ Health Sci Eng, 7(1), 15-24.

Zazouli M., Nasseri S., Mahvi A., Gholami M., Mesdaghinia A. and Younesian M. (2008), Retention of humic acid from water by nanofiltration membrane and influence of solution chemistry on membrane performance, Iranian J Environ Health Sci Eng, 5(1), 11-18.

Zhang J., Jiang D. and Peng H.-X. (2014), A pressurized filtration technique for fabricating carbon nanotube buckypaper: Structure, mechanical and conductive properties, Microporous Mesoporous Mater., 184(0), 127-133.

Zhao C., Xu X., Chen J. and Yang F. (2013), Effect of graphene oxide concentration on the morphologies and antifouling properties of PVDF ultrafiltration membranes, J Environ Health Sci Eng, 1(3), 349-354. 